\title{
INSTAGRAM AND STUDENTS' HIGHER ORDER THINKING SKILL OF CREATING
}

\author{
Niken Dwiretno Galuh Agrikaltarini ${ }^{1}$, Susanto Susanto ${ }^{2}$, Ahmad Munir $^{3}$ \\ Postgraduate Program of English Education and Literature, State University of Surabaya, Indonesia ${ }^{1,2,3}$ \\ niken.dwiretno@gmail.com ${ }^{1}$; susantoniki@gmail.com ${ }^{2 ;}$ ahmadmunir@unesa.ac.id ${ }^{3}$
}

\begin{abstract}
This study aims to find out how students apply their creating skill as seen in their compositions posted in instagram. There were six tenth graders in one of the vocational high schools in Sidoarjo selected as the participants. The researcher collected the data which were in the form of written expressions (sentences) by observing students' creating skill processes as seen in their compositions posted in instagram. The data then were analyzed using the elements of each Brookhart's HOT skills of transfer, crititical thinking and problem solving. The findings showed that the activities of composing narrative texts and posting them in instagram account were belong to the real and meaningful transfer learning of near and far transfers. Next, students could fulfill eight out of eleven criteria of critical thinking skill. Last, only the last component of IDEAL problem solver that the students could not fulfill. All in all, the actual evidence of creating skill implementation when students created their compositions by the use of instagram is possible to justify.
\end{abstract}

Keywords: composition, HOT skills, social media.

\section{INTRODUCTION}

Technology plays prominent role for $21^{\text {st }}$ century learning. Therefore, it is imperative to be technology-savy teachers in this era. According to Edi (2015), teachers need to find out students' interests that relate to technology which can be carried out in teaching and learning in order the lessons can be delivered effectively and the students can develop their learning skills well. Regarding to technology, one of the products of technology that many people use nowadays are social media. There are many kinds of social media that people use in their daily life, and one of them is an instagram. It is defined as a mobile social networking application which its users can share photos and 60-second video (Handayani, 2016; Rouse, 2017).

Furthermore, instagram can actually be used as an online learning tool in language teaching. Since this application can be installed in smartphone, it can make the students more actively engage in learning the language skills (Yana \& Darwati, 2017). In terms of English learning specifically writing skill, instagram, as a learning tool, offers many interesting writing activities for students to practice. For example, teachers can post an interesting photo and ask students to compose a descriptive in the comments. This activity 
is called Caption It!. It can be used to train students' skill of creating since students use the photo to generate ideas for them to compose or produce a descriptive text (Handayani, 2016). Another example is students can use other accounts to navigate them to compose an essay or prepare a presentation. This activity can be used to train students' skill of creating since students use the accounts to help them to generate ideas for their essay as well as to design or plan a presentation (Savini, 2017). This skill of creating implemented by the students in their writing activities through instagram is part of higher order thinking skills (HOT skills).

Creating skill is described as an ability to put or reorganize elements together to form or produce a new and original pattern, structure, or product. The activities include generating, planning, and producing (Anderson, L.W., Krathwohl, D.R., Airasian, P.W., Cruikshank, K.A., Mayer, R.E., Pintrich, P.R., Rath, James., \& Wittrock, 2001). However, it is not enough to claim that when students compose an essay they have apply their creating skill. It is salient to dig in deeper the skill by analyzing other elements which include transferable, critical thinking, and problem solving skills that can be seen in their composition.

In terms of transferable, critical thinking, and problem solving skills, Brookhart (2010) defines them as higher order thinking skills as well. Transfer is defined as 'meaningful learning' in which students are able to relate their learning to other things beyond those they were taught to associate with it. Furthermore, Haskell (2000) in his book "Transfer of Learning" mentions six levels of transfer. The first level is nonspecific transfer. It is a skill that relates to past learning that people naturally acquire or we can say this as everyday experience of transfer. The second level is application transfer. It refers to the ability of someone in applying what he/she has learned to a particular situation. The third level is context transfer. It refers to someone's ability to apply what he/she has learned in a quite different situation. The fourth level is near transfer. It is the ability to transfer previous knowledge to a new situation that is quite similar to previous situation. The next level is far transfer. It refers to someone's ability to apply what he/she has learned to a very different different situation from the original one which often involves in invention or product development. Finally, the last level is displacement or creative transfer. It refers to transferring learning that leads to the creation of new concept based on the discovery or similarities between the old and new knowldege/ learning. Level 4, 5, and 
6 are the real transfer learning since they require the learning of something new in order to make meaningful transfer.

Next, critical thinking skill is defined as the ability to apply wise judgement or produce a reasoned critique. In addition, it is also defined as the ability to to reason, reflect, and make sound decisions. There are eleven elements of critical thinking mentioned by Paul \& Elder (2008) which involve clarity (the ideas must be clear and easy to understand), precisions (exactly shows the ideas to the necessary level of detail), specificity (the ideas must be clear and have exact content as well as organization), accuracy (use correct grammar, spelling, punctuation, etc), relevance (the ideas suitable with the topic discussed), consistency (being consistent following the rules of the task given, e,g. organization, grammar used etc), logic (the ideas are reasonably make sense and suitable with the topic or task given), depth completeness (the ideas contain complexities and multiple interrelationship), significance (focusing on the important parts that are related to the topic, not trivial), breadth (the ideas must consider the possiblity of multiple point of views, perspectives, or solutions), and adequacy (the ideas are good and acceptable).

Last, problem solving skill is defined as the ability of learners to solve problems in their academic work and life as well as solving problems that are set for them and solving new problems that they encouter themselves, creating new as the solution. Moreover, Bransford \& Stein (1993) state components that learners must master in order to be called ideal problem solver. The components include identify the problem (students must be able locate the essential problem they encounter and describe in detail the nature of the problem), define and represent the problem (students must analyze the problem carefully and accurately and identify the key elements that had to be addressed), explore possible strategies (students must be able to explore various strategies to solve the problem), act on the strategies (students must actively apply the strategies to solve the problem), and look back and evaluate the effects of the activities (describe the outcomes and reflect the success or actions done to solve the problem).

Regarding to instagram and composition, it is prominent to study the actual evidence from instagram activities when students create their composition. In this way the application of creating skill can be investigated and justified by the use of instagram. This study tries to find out deeper on how students apply their creating skill through their 
composition posted in instagram by describing the HOT skills' elements found in their composition. Thus, the research question is formulated as follows:

What is the students' composition like as it is seen from their creating skill?

\section{METHOD}

It is a qualitative study that focuses on the case study design. The study focuses on how students apply their creating skill as seen in their compositions posted in instagram. As an observer, the researcher did an electronic observation by relying on historical records of online communication which were students' compositions posted in instagram. Since it is a qualitative study, the researcher only selected six tenth graders in one of vocational high schools in Sidoarjo as the participants. They consisted of three male and female students. They were also classified by their English proficiency, two students with high proficiency, two students with average proficiency, and two students with low proficiency of English.

The data of this study were in the form of written expressions (sentences) found and used by the students in their compositions posted in instagram. The researcher collected the data by observing students' creating skill processes as seen in their compositions posted in instagram. The data then were analyzed using the elements of each Brookharts' HOT skills of transfer, crititical thinking and problem solving.

\section{RESULT/ FINDINGS}

This part discusses the findings of HOT skills in terms of transfer, critical thinking, and problem solving applied by the students in the creating of narrative text compositions that they posted in instagram.

\section{Transferable skill}

Table 1. Transferable Skill Checklists of Students' Narrative Compositions Posted in Instagram

\begin{tabular}{lcccccc}
\hline \multirow{2}{*}{ Lesson Objectives } & \multicolumn{7}{c}{ Level of transfer } \\
\cline { 2 - 7 } & $\begin{array}{c}\text { Nonspecific } \\
\text { transfer }\end{array}$ & $\begin{array}{c}\text { Application } \\
\text { transfer }\end{array}$ & $\begin{array}{c}\text { Context } \\
\text { transfer }\end{array}$ & $\begin{array}{c}\text { Near } \\
\text { transfer }\end{array}$ & $\begin{array}{c}\text { Far } \\
\text { transfer }\end{array}$ & $\begin{array}{c}\text { Displacement/ } \\
\text { creative transfer }\end{array}$ \\
\hline Objective 1 & $\mathrm{X}$ & $\mathrm{X}$ & $\mathrm{X}$ & $\sqrt{ }$ & $\sqrt{ }$ & $\mathrm{X}$ \\
\hline Objective 2 & $\mathrm{X}$ & $\mathrm{X}$ & $\mathrm{X}$ & $\sqrt{ }$ & $\sqrt{ }$ & $\mathrm{X}$ \\
\hline
\end{tabular}


As stated in table 1, the finding of transferable skill is based on the objectives of the lesson given to students. From the lesson plan observation, there were two objectives that showed the application of creating skill. The first objective was composing narrative text of 'Malin Kundang' with alternatif ending and posting it in instagram account. The second objective was composing a narrative text with alternative middle and ending parts and posting it in instagram account. The students had to post the original text first then they posted the same text with alternative middle and ending parts

Both objectives showed that the activities were in the level of near transfer because it is related to the ability to transfer previous knowledge of writing story in a computer or blog to the new situation that is quite similar, which is by the use of social media instagram. Moreover, they also belong to far transfer level that is related to product development and invention. It happened because the activities required students to change the middle and ending parts of the story which were different from the original one. 


\section{Critical thinking skill}

Table 2. Critical Thinking Checklists for Students' Narrative Composition Task 1 Posted in Instagram

\begin{tabular}{|c|c|c|c|c|c|c|c|c|c|c|c|}
\hline \multirow[b]{2}{*}{ Participants } & \multicolumn{11}{|c|}{ Criteria } \\
\hline & Clarity & Precisions & Specificity & Accuracy & Relevance & Consistency & Logic & $\begin{array}{c}\text { Depth } \\
\text { Com- } \\
\text { pleteness }\end{array}$ & Significance & Breadth & Adequacy \\
\hline SM1 & $\sqrt{ }$ & $\sqrt{ }$ & $\mathrm{X}$ & $X$ & $\sqrt{ }$ & $\mathrm{X}$ & $\sqrt{ }$ & $\sqrt{ }$ & $X$ & $\sqrt{ }$ & $\sqrt{ }$ \\
\hline SF2 & $\sqrt{ }$ & $\sqrt{ }$ & $\sqrt{ }$ & $X$ & $\sqrt{ }$ & $\mathrm{X}$ & $\sqrt{ }$ & $X$ & $\sqrt{ }$ & $\sqrt{ }$ & $\sqrt{ }$ \\
\hline SM3 & $\sqrt{ }$ & $\sqrt{ }$ & $\sqrt{ }$ & $\mathrm{X}$ & $\sqrt{ }$ & $\mathrm{X}$ & $\sqrt{ }$ & $\mathrm{X}$ & $\sqrt{ }$ & $\sqrt{ }$ & $\sqrt{ }$ \\
\hline SF4 & $\sqrt{ }$ & $\mathrm{X}$ & $\sqrt{ }$ & $X$ & $\sqrt{ }$ & $\mathrm{X}$ & $\sqrt{ }$ & $\mathrm{X}$ & $\sqrt{ }$ & $\sqrt{ }$ & $\sqrt{ }$ \\
\hline SM5 & $\sqrt{ }$ & $\mathrm{X}$ & $\sqrt{ }$ & $X$ & $\sqrt{ }$ & $\mathrm{X}$ & $\sqrt{ }$ & $X$ & $\sqrt{ }$ & $\sqrt{ }$ & $\sqrt{ }$ \\
\hline SF6 & $\sqrt{ }$ & $X$ & $\sqrt{ }$ & $X$ & $\sqrt{ }$ & $X$ & $\sqrt{ }$ & $X$ & $\sqrt{ }$ & $\sqrt{ }$ & $\sqrt{ }$ \\
\hline
\end{tabular}

Table 2 shows the criteria of critical thinking skill that the students fulfilled when they composed narative text of 'Malin Kundang' with altenative ending. SM1 and SF2 are the high proficiency students, SM3 and SF4 are the average proficiency students, and SM5 and SF6 are the low proficiency students. Based on the table, all students successfully fulfilled the criteria of clarity, relevance, logic, breadth, and adequacy. However, they failed to fulfill the criteria of accuracy and consistency. Moreover, five of them fulfilled the criteria of specificity and significance. There are three students (SM1, SF2, and SM3) fulfilled the criterion of precisions. Finally, SM1 as the high proficiency student, is the only person who could fulfill the criterion of depth-completeness. 
Table 3. Critical Thinking Checklists for Students' Narrative Composition Task 2 Posted in Instagram

\begin{tabular}{|c|c|c|c|c|c|c|c|c|c|c|c|}
\hline \multirow[b]{2}{*}{ Participants } & \multicolumn{11}{|c|}{ Criteria } \\
\hline & Clarity & Precisions & Specificity & Accuracy & Relevance & Consistency & Logic & $\begin{array}{c}\text { Depth } \\
\text { Com- } \\
\text { pleteness }\end{array}$ & Significance & Breadth & Adequacy \\
\hline SM1 & $\sqrt{ }$ & $\sqrt{ }$ & $\sqrt{ }$ & $\mathrm{X}$ & $\sqrt{ }$ & $\mathrm{X}$ & $\sqrt{ }$ & $\mathrm{X}$ & $\sqrt{ }$ & $\sqrt{ }$ & $\sqrt{ }$ \\
\hline SF2 & $\sqrt{ }$ & $\sqrt{ }$ & $\sqrt{ }$ & $\mathrm{X}$ & $\sqrt{ }$ & $\mathrm{X}$ & $\sqrt{ }$ & $\mathrm{X}$ & $\sqrt{ }$ & $\sqrt{ }$ & $\sqrt{ }$ \\
\hline SM3 & $\sqrt{ }$ & $\sqrt{ }$ & $\sqrt{ }$ & $X$ & $\sqrt{ }$ & $\mathrm{X}$ & $\sqrt{ }$ & $\mathrm{X}$ & $\sqrt{ }$ & $\sqrt{ }$ & $\sqrt{ }$ \\
\hline SF4 & $\sqrt{ }$ & $\sqrt{ }$ & $\sqrt{ }$ & $X$ & $\sqrt{ }$ & $\mathrm{X}$ & $\sqrt{ }$ & $\mathrm{X}$ & $\sqrt{ }$ & $\sqrt{ }$ & $\sqrt{ }$ \\
\hline SM5 & $\mathrm{X}$ & $\sqrt{ }$ & $\mathrm{X}$ & $X$ & $\mathrm{X}$ & $\mathrm{X}$ & $\mathrm{X}$ & $\mathrm{X}$ & $\mathrm{X}$ & $\mathrm{X}$ & $\mathrm{X}$ \\
\hline SF6 & $\sqrt{ }$ & $X$ & $\sqrt{ }$ & $X$ & $\sqrt{ }$ & $X$ & $\sqrt{ }$ & $X$ & $\sqrt{ }$ & $\sqrt{ }$ & $\sqrt{ }$ \\
\hline
\end{tabular}

Table 3 shows the criteria of critical thinking skill that the students fulfilled when they composed narative text with alternative middle and ending parts. Based on the table, all of them failed to fulfill the criterion of accuracy, consistency, and depth-completeness. Furthermore, five of them fulfilled the criteria of clarity, precisions, specificity, relevance, logic, significance, breadth, and adequacy. Yet, one student (SM5) unfortunately could only fulfill precisions criterion.

\section{Problem solving skill}

Table 4. Problem Solving Checklists for Students' Narrative Composition Task 1 Posted in Instagram

\begin{tabular}{cccccc}
\hline & \multicolumn{5}{c}{ Components } \\
\cline { 2 - 6 } Participants & $\begin{array}{c}\text { Identify } \\
\text { the } \\
\text { problem }\end{array}$ & $\begin{array}{c}\text { Define and } \\
\text { represents the } \\
\text { problem }\end{array}$ & $\begin{array}{c}\text { Explore } \\
\text { possible } \\
\text { strategies }\end{array}$ & $\begin{array}{c}\text { Act on } \\
\text { the } \\
\text { strategies }\end{array}$ & $\begin{array}{c}\text { Look back and } \\
\text { evaluate the } \\
\text { effects of the } \\
\text { activity }\end{array}$ \\
\hline SM1 & $\mathrm{X}$ & $\mathrm{X}$ & $\sqrt{ }$ & $\sqrt{ }$ & $\mathrm{X}$ \\
\hline SF2 & $\sqrt{ }$ & $\sqrt{ }$ & $\sqrt{ }$ & $\sqrt{ }$ & $\mathrm{X}$ \\
\hline SM3 & $\sqrt{ }$ & $\sqrt{ }$ & $\sqrt{ }$ & $\sqrt{ }$ & $\mathrm{X}$ \\
\hline SF4 & $\sqrt{ }$ & $\sqrt{ }$ & $\sqrt{ }$ & $\sqrt{ }$ & $\mathrm{X}$ \\
\hline SM5 & $\sqrt{ }$ & $\sqrt{ }$ & $\sqrt{ }$ & $\sqrt{ }$ & $\mathrm{X}$ \\
\hline
\end{tabular}


ANGLO-SAXON, VOL. 10, NO.1:1- 14 July 2019

P-ISSN 2301-5292

E-ISSN 2598-9995 
Table 4 shows the components of problem solving skill that the students fulfilled in composing narative text of 'Malin Kundang' with alternative ending. Based on the table, all of them successfully exploring the possible strategies and acting on the strategies. However, one student (SM1) failed to identify the problem and define as well as represent the problem. In addition, all of them failed to fulfill the last component since they were not assigned to do self reflection or evaluation of the activities they have done.

Table 5. Problem Solving Checklists for Students' Narrative Composition Task 2 Posted in Instagram

\begin{tabular}{cccccc}
\hline & \multicolumn{5}{c}{ Components } \\
\cline { 2 - 6 } Participants & $\begin{array}{c}\text { Identify the } \\
\text { problem }\end{array}$ & $\begin{array}{c}\text { Define and } \\
\text { represent the } \\
\text { problem }\end{array}$ & $\begin{array}{c}\text { Explore } \\
\text { possible } \\
\text { strategies }\end{array}$ & $\begin{array}{c}\text { Act on the } \\
\text { strategies }\end{array}$ & $\begin{array}{c}\text { Look back and } \\
\text { evaluate the } \\
\text { effects of the } \\
\text { activity }\end{array}$ \\
\hline SM1 & $\sqrt{ }$ & $\sqrt{ }$ & $\sqrt{ }$ & $\sqrt{ }$ & $\mathrm{X}$ \\
\hline SF2 & $\sqrt{ }$ & $\sqrt{ }$ & $\sqrt{ }$ & $\sqrt{ }$ & $\mathrm{X}$ \\
\hline SM3 & $\sqrt{ }$ & $\sqrt{ }$ & $\sqrt{ }$ & $\sqrt{ }$ & $\mathrm{X}$ \\
\hline SF4 & $\sqrt{ }$ & $\sqrt{ }$ & $\sqrt{ }$ & $\sqrt{ }$ & $\mathrm{X}$ \\
\hline SM5 & $\sqrt{ }$ & $\mathrm{X}$ & $\mathrm{X}$ & $\mathrm{X}$ & $\mathrm{X}$ \\
\hline SF6 & $\sqrt{ }$ & $\sqrt{ }$ & $\sqrt{ }$ & $\sqrt{ }$ & $\mathrm{X}$ \\
\hline
\end{tabular}

Table 5 shows the components of problem solving skill that the students fulfilled in composing narative text with alternative middle and ending parts. Based on the table, all students suceessfully identified the problem. Yet, one student failed to define and represent the problem, explore possible strategies, and act on the strategies. Similarly, all students failed to fulfill the last component due to the same reason as mentioned previously.

\section{DISCUSSION}

This part discusses the details explanation of the findings. The explanation will be connected with theories in literary review mentioned in the introduction part to support the findings.

\section{Transferable skill}

As mentioned in findings, the activities in both objectives showed they were in the level of near and far transfers. Based on the transfer of learning taxonomy stated by Haskell (2000), the activities are in level 4 and 5 of the taxonomy. In near transfer level, students transferred their knowledge of writing with computer or in a blog to a new situation that is quite similar by the use of instagram. It is in line with the definition of near 
transfer that refers to the ability to transfer previous knowledge to a new situation that is quite similar to previous situation. Furthermore, in far transfer level, students were asked to change the middle and ending parts of the story which were different from the original one. It is in line with the definition of far transfer that refers to the ability to apply what someone has learned to a very different situation from the original one that often involves invention and product development. The real transfer learning is the transfer that requires the learning of something new in order to make meaningful transfer. Thus, near and far transfer meet the criterion of the real transfer learning.

\section{Critical thinking skill}

The criteria used to analyze students' critical thinking skills are based on the eleven elements of critical thinking mentioned by Paul \& Elder (2008). Students need to consider the elements to be able to express their ideas critically. Furthermore, the findings in the first task in students were asked to compose 'Malin Kundang' story with alternative ending showed that they fulfilled the criteria of clarity (the compositions were clear and easy to understand), relevance (the compositions were suitable with the topic which was about narrative text), logic (the compositions were reasonably make sense and suitable with the topic or task given which was narrative text of 'Malin Kundang'), breadth (the students considered other possible resolutions in the ending part), and adequacy (the compositions were good and acceptable).

However, they failed to fulfill the criterion of accuracy. They still make little mistakes in grammar (especially the use of past tenses), punctuation, paragraph spacing/format (for example, SM1 composed a long paragrah of the story and SF6 composed a short paragraph of the story), and inappropriate choice of words. They also failed to fulfill the criterion of consistency in which they were supposed to be consistent following the rules of the task given which are the use of past tenses in the composition, fix organization of narrative text (orientation, complication, resolution), and the content that need to be suitable with the topic or task given. Yet, all of them made grammar mistakes of past tenses. Moreover, one student (SM1) could not be consistent with his organization because it is difficult to find which one is the complication of the story. He also changed the whole content of the story instead of changing the ending part of the story. 
Next, There were three students (SM1, SF2, and SM3) fulfilled the criterion of precisions. They could exactly showed the composition to the necessary level of detail especially when they described the characters' physical appearances and personality traits, the settings, and the characters' action/activities did in the story. With extraordinary choice of words, they could imaginatively describe them so the readers could imagine them clearly. Surprisingly, SM1 as the high proficiency student could not fulfill the criteria of specificity (the composition did not clear and did not have exact content, it also did not follow the organization of narrative text) and significance (the composition did not focus to the important part that need to be changed which was the ending of the story). However, SM1 is the only student who fulfilled the criterion of depth-completeness since he could showed the multiple interrelationship among the characters even though the complications and the resolutions of the story were absurd.

Meanwhile, the findings in the second task in which students were asked to change the middle and ending parts of narrative text they had chosen and posted in their instagram account showed different results compared to the first task. In the second task, all students failed to fulfill the criteria of accuracy, consistency, and depth-completeness. The reasons behind the failure of fulfilling accuracy and consistency criteria were the same as the first task. All of them still made mistakes in grammar, punctuation, paragraph spacing/format, capitalization, and inappropriate choice of words. One student (SM5) even had bad organization since some parts of the story were missing and the ending of the story remained the same. In terms of depth-completeness, none of the composition contained complexities and multiple interrelationship among the characters of the story as well as the complications of the story.

Furthermore, almost all of them fulfilled the criteria of clarity (the composition was clear and easy to understand), precisions (they exactly showed the composition to the necessary level of detail with their choice of words in which they imaginatively described the characters' physical appearances and personality traits, the settings, and the characters' action/activities did in the story), specificity (the composition was clear and had exact content as well as organization), relevance (the composition suitable with the topic assigned), logic (the composition was reasonably made sense and suitable with the task given), significance (the composition focused on the important parts which were the changing of middle and ending parts of the story), breadth (the students considered other 
possible middle and ending parts as the complication and resolution of the story), and adequacy (the story was good and acceptable). Unfortunately, one student (SM5) could only fulfill precisions criterion due to incomplete of some parts of the story as well as the ending of the story which remained the same.

\section{Problem solving skill}

IDEAL as the acronym of problem solving components stated by Bransford \& Stein (1993) were used to analyze the students' problem solving skill. In the first task five of them could identify the problem and define as well as represent the problem in which they could locate the problem/ or complication of the story and identify the key element of the complication to create the resolution. These components were reflected on the ending part of the story they had made which was suitable for the solution to the complication. However, one student (SM1) could not identify the problem and define as well as represent the problem because based on the organization of his composition it is difficult to find out the complication of the story.

Furthermore, all students could explore possible strategies as the alternative solutions and act on the strategies in which they apply it through the alternative ending as the resolution. SM1 specifically, explored and acted the possible strategies by changing the whole story of the original text of 'Malin Kundang'. Yet, all of them did not look back and evaluate the effects of the activity in which they had to describe the outcomes and reflect the success or actions done to solve the problem since they were not assigned to do self reflection or evaluation of the activities they have done.

Likewise, in the second task, all students could identify the problems of the original text. Therefore, they could make alternative problem/complication of the story. Five of them could define and represent the problem in which they can identify the key element or major complication in original text and it was reflected in their alternative middle part of the story. However, one student (SM5) could not identify the key element of the complication due to incomplete parts of the story he made. Moreover, five of them were also able to explore possible strategies and act on the strategies by giving alternative ending/resolution to the story they composed. Yet, one student (SM5) could not explore possible strategies and act on the strategies to compose altenative ending/resolution because the ending of the story that he made remained the same as the original text. Last, 
due to the same reason mentioned previously when the students did the first task, all of them did not look back and evaluate the effects of the activity.

\section{CONCLUSION}

Students' activities of composing narrative texts and posting them in their instagram account are the implementation of HOT skill of creating. In details, this creating skill activities also reveal other HOT skills of transfer, critical thinking, and problem solving that were applied by the students in the process of composing narrative texts and posting them in their instagram account. In terms of transferable skill, the activities showed they were belong to the real and meaningful transfer learning of near and far transfers. Meanwhile, the students might not fulfill all criteria of critical thinking skills, but most of them could fulfill some of the criteria which include clarity, precisions, specificity, relevance, logic, significance, breadth, and adequacy. Finally, most students could implement four components of problem solving skills except one component of looking back and evaluating the effects of the activity. It happened because they were not assigned to do self reflection or evaluation of the activities they have done. To conclude, the actual evidence of creating skill implementation when students created their compositions by the use of instagram is possible to justify.

\section{REFERENCES}

Anderson, L.W., Krathwohl, D.R., Airasian, P.W., Cruikshank, K.A., Mayer, R.E., Pintrich, P.R., Rath, James., \& Wittrock, M. C. (2001). A taxonomy for learning, teaching, and assessing. A revision of Bloom's taxonomy of educational objectives. (Abridged e). New York: Longman.

Bransford, John D., Stein, B. S. (1993). The Ideal Problem Solver: A Guide for Improving Thinking, Learning, and Creativity (Second Ed.). New York: W.H. Freeman and Company.

Brookhart, S. M. (2010). How to assess higher-order thinking skills in your classroom. Alexandria, Virginia USA: ASCD.

Edi, W. (2015). English Language Teaching and Learning Issues in Batam Learners ' 
ANGLO-SAXON, VOL. 10, NO.1:1- 14

July 2019

P-ISSN 2301-5292

E-ISSN 2598-9995

Perception via Facebook Dialog Journal. ANGLO-SAXON: Jurnal Ilmiah Program Studi Pendidikan Bahasa Inggris, 6(2), 46-58.

Handayani, F. (2016). Instagram as a teaching tool? Really? In ISELT FBS Universitas Negeri Padang 4(1) (pp. 320-327).

Haskell, R. E. (2000). Transfer of Learning: Cognition, Instruction, and Reasoning. Academic Press.

Paul, Richard., \& Elder, L. (2008). The miniature guide to critical thinking concepts and tools (Fifth Ed). California: Foundation for Critical Thinking Press.

$\begin{array}{lllll}\text { Rouse, } & \text { M. (2017). Instagram. } & \text { Retrieved }\end{array}$ https://searchcio.techtarget.com/definition/Instagram

Savini, A. (2017). Instaclass: eight ideas for using instagram in the classroom. Retrieved from http://www.cambridge.org/elt/blog/2017/05/04/8-ideas-using-instagram/

Yana, D., \& Darwati, F. F. (2017). The Implementation of Android-Based Application as a Media for Teaching English in Simple Present Tense. ANGLO-SAXON: Jurnal Ilmiah Program Studi Pendidikan Bahasa Inggris, 8(2), 158-165. 